\title{
The Model of Formation of Project Culture of the Future Pedagogue in the Course of Vocational Training
}

\author{
Dmitry A. Krylov ${ }^{1}$, Nikolai V. Kuzmin ${ }^{1} \&$ Sergey G. Korotkov ${ }^{1}$ \\ ${ }^{1}$ Mari State University, Yoshkar-Ola, Russia \\ Correspondence: Dmitry A. Krylov, Department of theory and methodology of technology and vocational \\ education, Mari State University, Yoshkar-Ola, 42000, Russia. E-mail: krilda@mail.ru
}

\author{
Received: February 21, $2015 \quad$ Accepted: March 15, $2015 \quad$ Online Published: April 29, 2015 \\ doi:10.5539/res.v7n8p28 URL: http://dx.doi.org/10.5539/res.v7n8p28
}

\begin{abstract}
Formation of project culture contributes to improving the training of qualified pedagogues, competitive and in demand in the labor market. In this regard, this article reveals the pedagogical model that would allow taking into account modern realities effectively shaping project culture of the future pedagogue. Major approaches to the study of this problem were the personality-centered and system approaches, which allows you to create a symbiosis of project culture the future pedagogue with the integration of a technocratic and humane, research and prediction, information and educational and socio-conversion started project activities. Features of the model of formation of project culture of the future pedagogue are in combination offered by the authors of the functional components (information, procedural, emotional and resultative) and technologies formation of project culture represented in the model of four blocks (motivational target, intellectual and substantive, organizational-activity and reflective-evaluative). Materials of this article can be useful for the management and staff of higher vocational education institutions, also for researchers concerned with the formation project culture of teachers and students.
\end{abstract}

Keywords: project culture, modeling, vocational training, components

\section{Introduction}

The ongoing process of globalization of cultural and educational space, part of which are integrative processes, carry a great potential for the development of humanitarian education in our country. Prospects for updating it makes strongly the task of preparing a professional capable of designing their own activities in different socio-cultural situations, ready to find approaches for solutions to problems arising independently of the particular circumstances, to develop a specific strategy of professional thinking, behavior and activity.

The basic condition for implementing these requirements, defining reference points higher pedagogical education, is the transition to a new educational paradigm, the dominant factor which acts culture, education of "person culture".

Today it is especially important that pedagogical education became practically humanity-knowledge, a kind of pedagogical anthropology.

Values and norms of culture, art and morality all the achievements of the spiritual sphere of life should create an atmosphere of turning to the human person, to penetrate all structures of complete pedagogical process, ensure its focus on humanitarian and personal development of future specialists.

In the modern technocratic society, whose development is characterized by extraordinary mobility, variability, project type of culture begins to dominate, becoming one of the central mechanisms of the future-creating, discovering at the same time universal and synthetic nature of the project activities, which traces compound technocratic and humane, research and prediction, information educational and socio-conversion began, and this leads to that of each educator is necessary to master project activity in its different versions (Filimonyuk, 2008; Shaidullina et al., 2015).

\section{Literature Review}

The phenomenon project culture is not only increasingly attracted the attention of researchers, but also to become one of the most important components of modern educational process. Can be caused a lot of arguments 
in favor of the need to develop a culture of the project. Firstly, the projection is a form of problem-developmental education. Secondly, the projection changes the type of thinking of project participants, approaching it to the needs of the XXI century. Third, the projection defines a new, modern, innovative appearance of any educational institution. Fourth, the projection implements the idea of personality and creative pedagogy. Fifth, the projection changes competitiveness teacher himself on the labor market (Khairullina, Valeyev, Valeyeva, Valeyeva, Leifa, Burdukovskaya, \& Shaidullina, 2015).

In addition, according to many researchers prominent feature of contemporary culture has constructive, transformative character (Genisaretsky, 1989; Jones, 1986; Serikov, 1999, etc.).

One of the conditions for the development of project culture is its continuity. But the more actively begin to show themselves centrifugal forces of project culture, the stronger the pull of man to the norms of, patterns of behavior of his generation, or at least its sociocultural microenvironment. From here mass conversion to religion, revival of philanthropy, charity, etc.

Analysis of the definitions of project culture of Kolesnikova, Markov, Radionova et al., allowed to understand it as a way of creative self-realization, which produces tangible world, which is the bearer of the ideals and values of the spiritual world, transforms the living environment in accordance with these ideals and values (Krylov, 2010).

The project is based on the culture of the pedagogue the project competence including a knowledge and abilities on the basics of design, of formation of creative qualities and abilities of the individual, his ability to construct their own innovative technological approaches to solving problems in a dynamically changing non-standard situations, creative activity in the transforming activities directed at optimizing and aesthetic organization of the living environment.

As a method of knowledge modeling in pedagogical sciences has been used sufficiently intense with the 80 -ies of XX century. In the last decade, the problem of modeling becoming and functioning of the educational systems also do not remain without attention pedagogues and researchers. The philosophers B. A. Glinski, B. S. Hraznova, E. P. Nikitin, V. A. Stoff and pedagogues A. I. Archangel, A. P. Belyaev, V. P. Bespalko, V. I. Zhuravlev, A. A. Kirsanov V. V. Krajewski, I. I. Loginov et al., are devoted their works of modeling as a scientific method (Sidorenko, 1984).

V. A. Stoff understands modeling as "the construction of models, their examination and verification, in the proof of the truth and the realness for true knowledge" (Stoff, 1986). This definition contains four attributes:

1) Model—A mental representation or materially implemented system;

2) It reflects the object of study;

3) It is able to replace the object;

4) Its study provides new information about the object.

The objective ability to model B. A. Glinskij considers combination of the elements included in the integrity of a subject. Elements included in the thing, should naturally consistent with each other, however, the elements and the relations that constitute model must meet the elements and relations belonging to the original. The original object is directly interested researcher and moving model, but under the original object is understood in its holistic qualitative and quantitative specificity in all the richness of the various properties object, connections and relationships, and the object with the properties, connections and relationships that are directly interested researcher.

In general, modeling - the research of any phenomena, processes or systems of objects by constructing and studying their models.

The object of our modeling is the project culture of the future pedagogue. Given the structure, particularly the process being studied and chosen approach was an attempt of designing a pedagogical model that would enable taking into account the contemporary realities to carry out the formation of project culture of the future pedagogue.

\section{Methodological Framework}

When creating model, we took into account a variety of approaches to the project of pedagogical processes. One of them is to ensure that the learning process is designed to fulfill the classical function - to transfer knowledge, to develop practical skills of the future specialist. The essence of the second approach - the stimulation of creative activity of the learner, the direction of its essential powers and cognitive activity in the independent 
acquisition of knowledge (learner-the subject of educational and pedagogical process). The third approach implies rigid control of the process of becoming a specialist in which the use of a variety of learning technologies guarantee a high level of training and, therefore, ready for professional activity. Along with the above mentioned, in the modeling process, we found it expedient to turn to modern ideas of systems theory. Firstly, the systems analysis performs as methodological basis for the study of complex objects and processes, which include most of the social processes, including the processes of learning, education, the formation of personality and its readiness for a certain kind of activity. Secondly, a systematic approach does not exclude the special and traditional research methods, but rather complements them. (Filimonyuk, 2008).

By defining cumulative positive role of a systems approach to the modeling of pedagogical processes, we proceeded from the following:

- System analysis allows to reveal a wider cognitive reality compared to that achieved specially-scientific methods;

- Search for specific integrity mechanisms and the elicitation of a sufficiently complete typology of its bonds are the basis for the construction of new schemes of explanation, knowledge, research;

- The complexity of the studied object is displayed at the system analysis through the great variety of its "internal" and "external" links, which enables us to consider a several different articulations of the same object of the system to be studied (ie, a good adequacy of the studied system is only ensured in the construction of a set of models, each of which can describe only certain aspects of the system).

In other words, applying the principle of systems to the modeling of the formation of the project culture of the pedagogue, we considered it as a subsystem of the general content of vocational and pedagogical training.

\section{Results and Discussion}

Pedagogical model constructed on the basis social demand of society in the training of the pedagogue, the requirements of the federal state standard to the level of education and vocational training pedagogues and included: the functional components of the project culture of the pedagogue, forming technology of project culture pedagogue and subsystem analysis and correction system. The final result of the simulated system was the high level of project culture the future pedagogue (Figure 1).

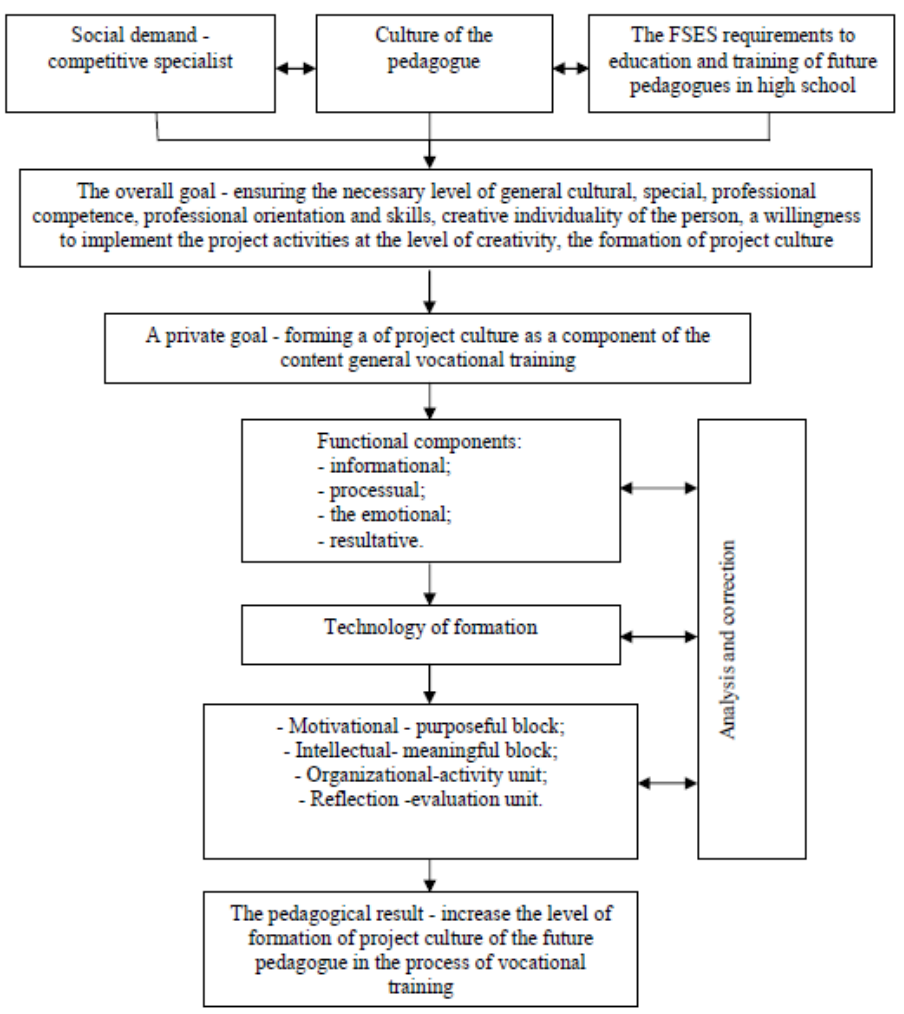

Figure 1. Model of formation of the project culture of the future pedagogue in the course vocational training 
We'll analyze components of the model of formation of project culture of the future pedagogue in the course of vocational training.

The starting point in it appears social order for pedagogue training, as reflected in the principles of the state policy in the field of education, and understands us as an aggregate of interests and needs of society to a specialist in this socio-economic and political development stage. It should be noted that the current domestic education is characterized by orientation to international standards, the recognition of it as one of the main national priorities, renaissance spiritual foundations of the individual in continuing education, an increase of humanistic principles and universal values that radically changes the requirements for a specialist in the field of education: time requires a large-scale, bright, creative personality, capable of being the bearer of culture accumulated values, deeply owns methods of pedagogy, art, professional communication, modern pedagogical technologies (Gorovaya, 1995).

The main goals of the educational process in state institution should be execution the social order. The central component of the model is the backbone goal- building a project culture of future pedagogues.

As the Gorovaya (1995), search requirements for modern specialist are currently being implemented in several directions and are reflected in the various documents. One of them in recent years becomes a federal educational standard of higher professional education (FSES HPE).

As the same basic parameters of level of professional readiness in our model are the basic education; duration of training; the ratio of theoretical and practical training; the ratio of the composition, scope and content of the general scientific, general professional and specialized training; class professional tasks, which is ready to solve future specialist.

It should also be noted that the uniform standards of education orient the whole system of specialist training to achieve the goals of becoming a creative personality.

Thus, the educational standard in one case is the normative basis of the content of education and training, and in another - is the base definition of the purposes of functioning educational system focused on state policy in the field of education and interests of the individual.

Further consider the following components of the modeled system-goals. In the most general sense the goal-have expected, the desired state of the system, necessary to assume achieving the intended result. In addition, the goal is the core pedagogical category, linking together all the components of the educational system. It is from this perspective we come to the determination of the overall goal vocational training pedagogues in the projected model-providing the necessary level of general cultural, special, professional competence, professional orientation and skills, creative individuality of the person, a willingness to implement the project activities at the level of creativity, the formation of project culture.

There are three levels of goals: global, pedagogical and didactical. Under the global goals of our model is the social order of the system of teaching. Pedagogical goal was formulated on the basis of social order, and a description of the educational structure, which refers to the output of the educational system. Didactical goal was set through tasks that need to be solved in the course of specific forms of organization of educational process (lectures and practical classes, teaching practice, graduation design) (Filimonyuk, 2008).

From our point of such an approach to setting goals instrumental as it allows directionally provides training, to form his willingness to specific types of professional activity, to influence the development of personal qualities and properties of (Torkunova, Khairullina, Komelina, Volkova, \& Ponomarev, 2014).

In the model of the formation of the project culture of the pedagogue is regarded as a piece of content of general professional training. At the same time, we relied on the idea of a functional model of the pedagogue built N.V. Kuzmina, according to the principle the cumulative scale and developed for the analysis of this activity (Kuzmina, 1970). Defining the functional elements of project culture as a basic connection between a desired final state of the system and the desired result, we have identified the following ones:

1) Information component-knowledge of the nature, content, structure project culture, ways and means of implementation of project activities; mastering orientation based on individual and creative nature of the design activity of the pedagogue.

2) The procedural component—-the ability to carry out project activities in the parameters of "creativity" and "personality".

3) The emotional component—an interest in the project culture, design, modeling, mentally experimentation, self-assertion, pedagogical creativity. 
4) Efficient component- the level of readiness for the implementation of educational plans in specific types (types) of learning; the level of development of project culture.

On the functional components oriented and technology forming of project culture, presented in four blocks of the model:

1) Motivational-target block. It is obvious that the formation of project culture is impossible without the process of mastering this quality does not become a need of every student.

But needs by themselves are not a trigger action. Before becoming the core of the business, the need to be understood. Perceived need for taking concrete, substantive views, becoming a motive activity (Markova, 1996).

It is necessary to identify those internal needs, motives future pedagogue who may be supporting in the process of project culture. Need special conditions for the formation of positive motivation. This is to ensure the transfer of internal position of the future pedagogue of the object of pedagogical influence in the active subject of the educational process, the use of new technologies in the educational process, forming a certain style and paradigms of teaching the history of education, human studies. The latter has an interdisciplinary nature, connects philosophy, sociology, pedagogy, psychology, and serves to highlight the dominant personality development. "Dominant boys - this affirmation in all areas (professional, moral, interpersonal, in the collective, self-improvement, etc.)." (Talanchuk, 1993)

If future pedagogues to enable both theoretically and practically explore their own dominance associated with self-expression, self-assertion in different areas and activities, to help him understand the truth, no doubt, from the youthful age of the dominant grow dominant life-real self-expression and self-assertion, which depends how he masters the basics of human studies, will be able to fulfill the objective for a social role and for that actively cultivate. "The path to self-improvement in all people one-through self-education. On examples of specific social roles need to open each their own specific tasks, their destination finally understand their life dominant and what to do to display it. A man without a dominant-it is a little gray, faceless person. How to be- to draw this conclusion independently each." (Yusufbekova, 1991)

Due to the fact that in practice the pedagogue to a greater extent have to rely on the continuous change of motivation, arising under the influence of circumstances, this translation was carried out directly mainly procedural aspect of training.

Motivational target block is aimed at creating conditions for the formation of students of theoretical knowledge about the features, nature, structure project culture pedagogue, how to implement the project activities of the pedagogue, the production of a systematic approach to solving standard and non-standard tasks in this activity, the formation of complex projective abilities in quasiprofessional educational activities, the development of interest in pedagogical design.

2) Intellectual and meaningful unit associated with the semantic aspect project culture. Conceptually, the contents of which stimulates the formation project culture, we have considered as a set of teaching-activity-related modules. Module - this is some systemic organization of the content of the material, which gives mastering specialists to solve a particular range of professional challenges (Verbitsky, 1991).

Intellectual and meaningful unit is connected to familiarize students with the theoretical foundations of project culture; basics of organization and planning of specific activities; disclosure of the role of theoretical and practical bases of formation of the various elements of project culture; the formation of the gnostic, projective, design-planning and organizational skills, and the development of creative thinking.

3) Organization-activity unit includes a choice of forms, methods and tools to assist in the formation and development of pedagogue project culture.

4) Reflexive and evaluation unit is focused on the establishment of signs of formation at students of project culture and identification on the basis of their levels of its severity. That they were taken by us as a basis for pedagogical model results system, and among the evaluated attributes include:

a) Information-awareness of the importance of project culture and design activities as a factor in the intensification of pedagogical work, mastery of basic skills necessary for the activity, the knowledge requirements for modern personality of the pedagogue;

b) Motivational — orientation of the person of the future pedagogue to professional and educational activities, the desire to acquire knowledge and skills necessary to perform projective activity, the belief that a more effective implementation of the educational process in the school must have a high level of project culture;

c) Substantial — knowledge of the nature, structure and functions of project culture, means and methods of its 
formation and development;

d) Operational - the ability to determine the presence of features, structure, nature, functions of project culture, the best use of methods and means of development.

\section{Conclusion}

Any educational system needs analysis and correction. In our research, we proceeded from the fact that in the analysis of pedagogical processes it is advisable to rely on the theory of studying special classes of systems. Among them stand out the theory of dynamical and control systems. Moreover, if the general theory of dynamical systems studies more processes to sustainability, in our case, are of particular importance unsustainable systems. Therefore, modeling the process of forming a project culture, we found it necessary to include a sub-system, the purpose of which is to ensure the management of all functional constraints and the system as a whole. In our model, this subsystem performs the function of the analysis and correction of the original project. And, as a benchmark for analytical and corrective actions were two groups of requirements: requirements for the content of the formation of the future pedagogue of project culture and requirements to the process.

Project culture as a system formation is a unity of pedagogical values, technologies, essential powers of personality, aimed at the creative implementation in various types of educational activities.

\section{Acknowledgments}

The authors thank all participants of this study for their kind cooperation.

\section{References}

Filimonyuk, L. A. (2008). Formation of project culture the teacher in the process of training (Unpublished doctoral dissertation). North Caucasian Federal University, Stavropol, Russia.

Genisaretsky, O. I. (1989). Actual problems of research project culture. Technical aesthetics, 5, 22-27.

Gorovaya, V. I. (1995) Theoretical bases of specialist training in a multi-level higher education (Unpublished doctoral dissertation). North Caucasian Federal University, Stavropol, Russia.

Jones, J. C. (1986). Methods of designing; per. from English. Moscow: Mir.

Khairullina, E. R., Valeyev, A. S., Valeyeva, G. K., Valeyeva, N. S., Leifa, A. V., Burdukovskaya, E. A., \& Shaidullina, A. R. (2015). Features of the Programs Applied Bachelor Degree in Secondary and Higher Vocational. Education Asian Social Science, 11(3), 213-217.

Krylov, D. A. (2010). Formation of technological culture of future teachers. Kazan: Ofset-servise.

Kuzmina, N. V. (1970). Methods of pedagogical activity. Moscow: Pedagogy.

Markova, A. K. (1996). Psychology professionalism. Moscow: Knowledge.

Serikov, V. V. (1999). Education and personality-Theory and practice of designing pedagogical systems. Moscow: Logos.

Shaidullina, A. R., Krylov, D. A., Sadovaya, V. V., Yunusova, G. R., Glebov, S. O., Masalimova, A. R., \& Korshunova, I. V. (2015). Model of Vocational School, High School and Manufacture Integration in the Regional System of Professional Education. Review of European Studies, 7(1), 63-68. http://dx.doi.org/10.5539/res.v7n1p63

Sidorenko, V. F. (1984). Genesis project culture. Problems of Philosophy, 10, 86-99.

Stoff, V. A. (1986). Modeling and philosophy. Moscow: Science.

Talanchuk, N. M. (1993). System-synergetic concept of pedagogy and educational process. Kazan: ISSO RW.

Torkunova, J. V., Khairullina, E. R., Komelina, V. A., Volkova, N. V., \& Ponomarev, K. N. (2014). The Peculiarities of Qualitative Information, Analytical Maintenance Innovative and Educational Activity Technological Projection in Higher Educational Institution. Life Science Journal, 11(8), 498-503. Retrieved from http://www.lifesciencesite.com

Verbitsky, A. A. (1991). Active Learning in Higher Education: A contextual approach. Moscow: Higher School.

Yusufbekova, N. R. (1991). General principles of Pedagogical Innovation-Experience in the development of the theory of innovation processes in education. Moscow: Knowledge. 


\section{Copyrights}

Copyright for this article is retained by the author(s), with first publication rights granted to the journal. This is an open-access article distributed under the terms and conditions of the Creative Commons Attribution license (http://creativecommons.org/licenses/by/3.0/). 